\title{
Effect of Porosity on Strength Distribution of Microcrystalline Cellulose
}

\author{
Özgür Keleș, ${ }^{1,3}$ Nicholas P. Barcenas, ${ }^{1}$ Daniel H. Sprys, ${ }^{1}$ and Keith J. Bowman ${ }^{1,2}$
}

Received 6 January 2015; accepted 23 April 2015; published online 29 May 2015

\begin{abstract}
Fracture strength of pharmaceutical compacts varies even for nominally identical samples, which directly affects compaction, comminution, and tablet dosage forms. However, the relationships between porosity and mechanical behavior of compacts are not clear. Here, the effects of porosity on fracture strength and fracture statistics of microcrystalline cellulose compacts were investigated through diametral compression tests. Weibull modulus, a key parameter in Weibull statistics, was observed to decrease with increasing porosity from 17 to $56 \mathrm{vol} . \%$, based on eight sets of compacts at different porosity levels, each set containing $\sim 50$ samples, a total of 407 tests. Normal distribution fits better to fracture data for porosity less than $20 \mathrm{vol} \%$, whereas Weibull distribution is a better fit in the limit of highest porosity. Weibull moduli from 840 unique finite element simulations of isotropic porous materials were compared to experimental Weibull moduli from this research and results on various pharmaceutical materials. Deviations from Weibull statistics are observed. The effect of porosity on fracture strength can be described by a recently proposed micromechanics-based formula.
\end{abstract}

KEY WORDS: diametral compression test; finite element simulations; normal distribution; reliability; Weibull modulus.

\section{INTRODUCTION}

Mechanical properties of compacted powders are important in understanding the behavior of pharmaceutical materials during compaction, comminution (1), and as tablet dosage forms (2). Fracture behavior of Avicel powders has been reported for tensile (3), three point bending (4), and diametral compression (5) tests. However, even the nominally identical pharmaceutical tablets break at different loads (6-13). In this context, statistical functions such as Weibull distribution $(14,15)$ has been used in pharmaceutical sciences to describe tablet strength (6-13), pellet strength $(16,17)$, tablet brittleness (18), disintegration time (19), dissolution rate (20-22), stability (shelf life) (23), and compaction behavior (24). Tablet strength is also closely related to disintegration time $(25,26)$. Despite the common use of Weibull distribution in mechanical characterization of tablet dosage forms (6-13), the effect of porosity on Weibull statistics (27) and associated deviations (28) are unclear.

Conventionally, pharmaceutical tablets are defined as powder compacts consisting of active and inactive ingredients. Variables that influence tablet strength include porosity (8,29-31), porosity gradient, spatial distribution of pores (27), powder size distribution (32,33), powder aspect ratio

\footnotetext{
${ }^{1}$ Department of Mechanical, Materials, and Aerospace Engineering, Illinois Institute of Technology, Engineering 1 Building, Suite 243, Chicago, Illinois 60616-3793, USA.

${ }^{2}$ School of Materials Engineering, Purdue University, West Lafayette, Indiana 47907-2044, USA.

${ }^{3}$ To whom correspondence should be addressed. (e-mail: okeles@iit.edu)
}

(34), humidity (2), speed of compaction (8), coating (35), type of the fracture test $(8,36)$, loading rate during testing (18), tablet volume $(18,31)$, tablet material (6) and composition (18), lubrication $(33,37)$, temperature, and processing history of the compaction powder. Thermal fatigue and humidity fatigue can also affect tablet strength variability. Limited precision in commercial manufacturing of tablets also causes variations in tablet thickness, porosity, and weight, which, in turn, introduces variability in fracture strength $(7,9,12,13)$. In this context, Weibull or normal distributions are commonly used to quantify the fracture strength variation $(6,12)$.

The two-parameter Weibull distribution has been used to quantitatively describe the variation in fracture strength $(14,15)$ :

$$
F(\sigma, V)=1-\exp \left[-\frac{V}{V_{0}}\left(\frac{\sigma}{\sigma_{0}}\right)^{m}\right]
$$

where the failure probability $(F)$ is related to the uniaxial homogeneous tensile stress $(\sigma)$ and the specimen volume $(V) ; V_{0}$ is the normalizing volume. The Weibull modulus " $m$ " (shape parameter) has an inverse relationship with the scattering of strength, i.e., higher $m$ means lower strength variability and vice versa. Characteristic strength, $\sigma_{0}$, (scale parameter) corresponds to the failure probability at $63 \%$. Weibull distribution describes an increase in the failure probability with an increase in the sample volume. However, the stress term $\left(\sigma / \sigma_{0}\right)^{m}$ has the power of Weibull modulus, whereas the volume term $V / V_{0}$ has the power of 1 . 
Accordingly, the effect of specimen volume on the failure probability is limited for the compacts that have nominally the same size. Therefore, the volume term is assumed to be one, which should be included in a Weibull analysis when investigating the effects of specimen size or testing type $(38,39)$.

Weibull arrived at Eq. 1 based on a heuristic approach. Later, a direct mathematical relation between the Weibull distribution and Cauchy-type crack size distributions through fracture mechanics and weakest link theory was reported by Freudenthal (40). A physical relationship between the Weibull modulus and experimental crack size distribution of glass (41) was obtained by Jayatilaka and Trustrum (42). In general, if the crack size distribution is an inverse power law function $\mathrm{f}(a) \propto a^{-k}$, the fracture behavior obeys a Weibull distribution.

Weibull analysis requires that cracks do not interact, the crack size distribution does not change throughout the material and with the size, and that the material is under a uniaxial homogenous tensile stress. As a result, the Weibull modulus can only be regarded as a material property if the fracture behavior does not change with size and shape, in addition to the previous requirements.

However, in porous materials, stress interactions between pores (27) and other micromechanical inhomogeneities exist; thus, conventional Weibull theory cannot be applied. Nonetheless, any fracture data can be fitted to a Weibull distribution, but often deviations from Weibull behavior occur (28). Weibull modulus has been reported to change with the introduction of notches at various angles for graphite and silicon nitride specimens (43), which indicates an increased complexity in estimation of Weibull parameters for notched or embossed tablets.

Statistical investigation of fracture behavior requires a significant number of fracture tests to obtain reliable statistics. For ceramics, the number of specimens should be larger than 30 based on the standard ENV 843-1 (44). In addition, the relative error in estimated Weibull modulus does not decrease significantly for $N>40$ (45). These values, $N>30$, are larger than the suggested number of test specimens ten in European Pharmacopoeia (46) and six in US Pharmacopoeia (47). Pitchumani et al. (16) used a robotic compression tester to investigate crushing force of microcrystalline cellulose (MCC) pellets (particle size is $1010-1050 \mu \mathrm{m}, N=64$ ) and reported a Weibull modulus equal to 6. A similar approach can be extended to different testing geometries to obtain better statistics for pharmaceutical materials.

The only extended experimental study on fracture probability for MCC is by Sonnergaard (6), which reports coefficient of variation $(\mathrm{CV})$ for the crushing force together with an equation to calculate Weibull modulus from CV. One hundred tablets of Avicel PH 102 containing 0.5\% magnesium stearate were tested at three different porosity levels. The Weibull moduli for MCC decreased with increasing porosity (6). It should be noted that the crushing force is related to sample thickness. Therefore, these results cannot be directly used to infer effect of porosity on Weibull statistics.

It is important to have an understanding of the statistical distribution that describes fracture strength because a normal distribution of fracture strength is required for parametric inference tests such as the $t$ test, $F$ test, and analysis of variance (6). In addition, porosity directly affects fracture variability and fracture strength, which are directly related to the milling process $(6-9,12,13)$.
Accordingly, the aim of this study is to investigate the effect of porosity on fracture variability in Avicel PH 200 compacts through diametral compression test. Eight sets of about 50 specimens - a total of 407 specimens-were tested. Porosity levels between 17 and 56 vol.\% were chosen because this level includes common porosity levels for roller compacted ribbons and tablets (4). Chi-squared and Anderson-Darling goodness-of-fit tests were used to compare normal and Weibull distribution fits to fracture data. Experimental Weibull moduli were compared with the literature data and finite element simulations of microstructures containing uniform pores.

\section{MATERIALS AND METHODS}

\section{Experimental Procedure}

Avicel PH 200 microcrystalline cellulose (provided by FMC BioPolymer) powder was used to produce compacts; these compacts are used to simulate tablet porosity effects. According to the manufacturer, the nominal particle size of Avicel PH 200 is $180 \mu \mathrm{m}$. Powder was weighted using a Shimadzu AUW320 analytical scale with great care to avoid variability in weight, which, in turn, affects final thickness of the tablet. This is not the case for the commercial filling (8). Tablet porosity values were calculated using a true density of $1.46 \mathrm{~g} / \mathrm{cm}^{3}$ for MCC, which was based on a report from Sun (48).

Flat-faced cylindrical compacts in $\sim 10 \mathrm{~mm}$ diameter and $\sim 2.5 \mathrm{~mm}$ thickness were compressed using an Instron 5800 testing machine at a rate of $6 \mathrm{~mm} / \mathrm{min}$. This relatively slow compaction speed, $0.1 \mathrm{~mm} / \mathrm{s}$, alleviates the local temperature increases during compaction and limits the effect of temperature on fracture behavior of compacts (49). Dwell time was set to $0 \mathrm{~s}$. The testing machine was set to a load limit to achieve constant size for each tablet. Tablets in each porosity level were compacted nominally to the same size to avoid possible size effects on fracture strength and scattering. A decrease in porosity was achieved by compacting a smaller amount of powder at a lower compaction load (Table I).

After $\sim 24 \mathrm{~h}$ of compaction, a diametral compression test was performed on compacts using an Instron 5800 machine with a loading rate of $1 \mathrm{~mm} / \mathrm{min}$ except for the set with 36.1 vol. \% porosity, which was tested after 7 days. Fracture strength $\left(\sigma_{\mathrm{f}}\right)$ was calculated through $(50)$ :

$\sigma_{\mathrm{f}}=2 F / \pi D t$

where $F$ is the load at fracture, $D$ is the diameter and $t$ is the thickness of the compact. The ratio of the thickness ( $t$ ) and diameter $(d)$ of compacts was $\sim 0.25$, which is in the range of suggested values between $0.25 \leq \mathrm{t} / d^{\prime} \leq 0.5$ for diametral testing (7).

The number of specimens for each porosity level was set to $\sim 50$ to meet the ENV 843-1 standard requirement of at least 30 samples (44) and to obtain better statistical significance (45).

Weibull modulus and characteristic strength values were estimated by the maximum likelihood (ML) method because 
Table I. Weibull statistics of Avicel PH 200 compacts of the present study estimated from diametral compression tests

\begin{tabular}{|c|c|c|c|c|c|c|c|c|c|c|c|}
\hline \multirow[b]{2}{*}{ Material } & \multirow[b]{2}{*}{ M } & \multirow[b]{2}{*}{$\sigma_{0}(\mathrm{MPa})$} & \multirow[b]{2}{*}{$P($ vol. \%) } & \multirow[b]{2}{*}{$N$} & \multicolumn{2}{|c|}{$\chi^{2}$ test $P$ value } & \multicolumn{2}{|c|}{ AD test $P$ value } & \multirow[b]{2}{*}{ RH (\%) } & \multirow[b]{2}{*}{$S(\mathrm{MPa})$} & \multirow[b]{2}{*}{$w(\mathrm{mg})$} \\
\hline & & & & & Weibull & Normal & Weibull & Normal & & & \\
\hline $\mathrm{MCC}$ & $37(31-44)$ & $5.89 \pm 0.17$ & $16.8 \pm 0.6$ & 50 & 0.07 & 0.74 & 0.24 & 0.85 & 59 & 115 & 244 \\
\hline MCC & $32(28-38)$ & $5.67 \pm 0.18$ & $17.0 \pm 1.2$ & 50 & 0.24 & 0.53 & 0.26 & 0.79 & 47 & 115 & 243 \\
\hline MCC & $44(38-52)$ & $5.18 \pm 0.12$ & $18.4 \pm 0.6$ & 54 & 0.07 & 0.96 & 0.66 & $>0.99$ & 61 & 115 & 240 \\
\hline MCC & $24(20-29)$ & $3.75 \pm 0.21$ & $25.3 \pm 0.5$ & 50 & 0.02 & $0.01>$ & 0.61 & 0.14 & 53 & 70 & 219 \\
\hline MCC & $13(10-15)$ & $1.47 \pm 0.15$ & $36.1 \pm 1.3$ & 48 & 0.03 & 0.01 & 0.57 & 0.23 & 81 & 37 & 187 \\
\hline MCC & $11(9-13)$ & $0.79 \pm 0.08$ & $39.9 \pm 0.7$ & 50 & $0.01>$ & 0.01 & 0.17 & 0.17 & 50 & 21 & 172 \\
\hline MCC & $17(15-20)$ & $0.62 \pm 0.04$ & $45.4 \pm 0.7$ & 52 & 0.07 & 0.33 & 0.27 & 0.77 & 31 & 19 & 158 \\
\hline $\mathrm{MCC}$ & $9(8-11)$ & $0.21 \pm 0.03$ & $55.8 \pm 0.7$ & 53 & 0.98 & 0.36 & 0.95 & 0.87 & 57 & 8 & 129 \\
\hline
\end{tabular}

$P$ values of Pearson $\chi^{2}$ and Anderson-Darling (AD) goodness-of-fit test results for Weibull and normal distribution were generated using Mathematica 9 (Wolfram). A higher $P$ value indicates a better fit

$m$ is the Weibull modulus, $\sigma_{0}$ is the characteristic strength, $P$ is the porosity, $N$ is the number of the samples tested, $R H$ is the relative humidity during testing, $S$ is the compaction pressure, $w$ is the weight of the powder

ML estimators asymptotically become unbiased and minimum variance as the sample size increases (51). Pearson $\chi^{2}$ and Anderson-Darling (AD) tests were used to quantify the goodness of fit and demonstrate a preference between Weibull and normal distributions (ND). The difference between Pearson $\chi^{2}$ test and Anderson-Darling test is that AD test puts more emphasis on the upper and lower tail of the distribution than Pearson $\chi^{2}$ test.

\section{Theoretical Framework}

The details of the numerical procedure can be found in (27). Briefly, finite element simulations on 840 unique twodimensional microstructures containing uniform nonoverlapping circular pores up to 31 vol. \% were performed to obtain stress distributions under tensile loading. The stress distributions around pores were combined with classic fracture mechanics. On each pore surface, cracks were randomly generated from a normal distribution with a mean $=8.8 \mu \mathrm{m}$ and standard deviation $=2.8 \mu \mathrm{m}$. These microstructures contain non-overlapping circular pores of diameters: 48, 80, 120, and $160 \mu \mathrm{m}$. The fracture statistics in the simulations depend on pore-pore stress interactions, crack size, and crack orientation (52).

\section{RESULTS AND DISCUSSION}

\section{Effect of Porosity on Fracture Strength of Avicel PH 200 Compacts}

An increase in porosity should decrease the fracture strength of all dense brittle materials. All results here are consistent with this expectation. The change in fracture stress of Avicel PH 200 compacts with porosity is given in Fig. 3 together with Avicel PH 102 (53) and Emcocel 90M (37); all tests were performed on flat faced tablets under diametral compression. Cracks started at the center of the compacts (Fig. 1). Crack initiation and propagation at the center of the tablet indicates that the use of Eq. 2 and the calculated fracture strengths are valid. However, with porosity levels below the levels used in this study, flattening of the samples may compromise use of Eq. 2. This flattening will result in a deviation from the ideal contact situation, which is assumed for Eq. 2. Further discussion about the diametral compression test and a review of other mechanical tests that are performed on pharmaceutical tablets can be found in Podczeck (12).

Various functions have been suggested to describe the relationship between fracture strength and porosity such as power law $\sigma_{\mathrm{f}}=\sigma_{0} \exp (-b P / 100), \sigma_{\mathrm{F}}=\sigma_{0}(1-P / 100)^{h}(54), \sigma_{\mathrm{f}}=\sigma_{0} A_{\sigma}\left(1-P / P_{\mathrm{G}}\right)^{n}$ (55), and exponential $\sigma_{\mathrm{f}}=\sigma_{0} \exp (-b P / 100)(56,57)$. However, these equations lack a physical microstructure-based explanation for the decrease in $\sigma_{\mathrm{f}}$ with increasing porosity. Recently, finite element simulations on isotropic porous materials showed that there is a slow decrease in $\sigma_{\mathrm{f}}$ up to $5 \mathrm{vol} . \%$ porosity, followed by a steeper decrease between 5 and 20 vol.\% porosity, and a less steep decrease in $\sigma_{\mathrm{f}}$ for $P>20 \mathrm{vol} \%$ (27). Accordingly, there are two plateaus in the decrease in fracture strength: at low $P>5$ vol. \% and high porosity $P>20$ vol.\%. This $\sigma_{\mathrm{f}}$ versus $P$ behavior was fitted by

$\sigma_{\mathrm{f}}=\sigma_{\max }-\sigma_{\mathrm{dec}} \exp (-d / P)$

where $\sigma_{\max }$ is the maximum fracture strength at the lowest porosity level, $\sigma_{\mathrm{dec}}$ is related to the $\sigma_{\mathrm{f}}$ decrease up to the highest porosity, and $d$ is related to the steepness of the $\sigma_{\mathrm{f}}$ decrease (27). The higher the $d$ value, the steeper the fracture strength decrease. All the data in Fig. 3 were fitted to Eq. 3, assuming zero strength at $60 \mathrm{vol} . \%$ porosity, as shown by the dashed line in Fig. 3. Although the Avicel PH 102 and Emcocel 90M have similar nominal powder size $\sim 100 \mu \mathrm{m}$, fracture strength of the Emcocel $90 \mathrm{M}$ is higher, which can be due to testing conditions such as humidity. Overall, fracture strengths of three different MCC compacts follow a similar trend and Eq. 3 describes the change in $\sigma_{\mathrm{f}}$ with porosity.

The high porosity plateau starts around $P=35$ vol. \%. This observation can be related to the change in crack tip yielding that was reported for the Avicel PH 102 compacts at $\sim 30$ vol.\% (3) and the change in the degree of deformation at the particle level for compaction pressures above $\sim 80 \mathrm{MPa}$ (58). Furthermore, MCC compacts were reported to have a linear relationship between fracture strength and compaction pressure up to 27 vol. \% porosity corresponding to $100 \mathrm{MPa}$ and a nonlinear behavior for lower porosity levels (59). As the Avicel PH 200 compacts of $\sim 36$ vol. \% porosity were 


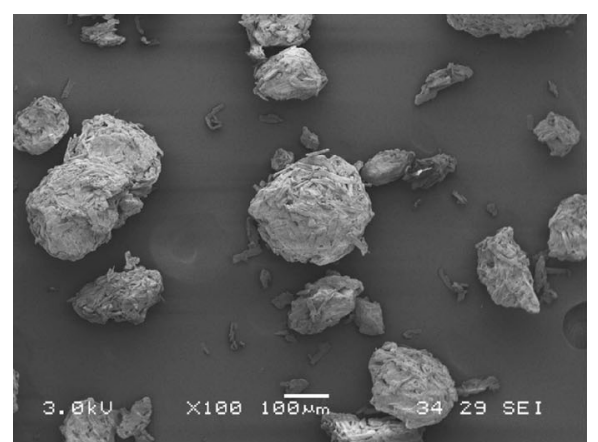

a

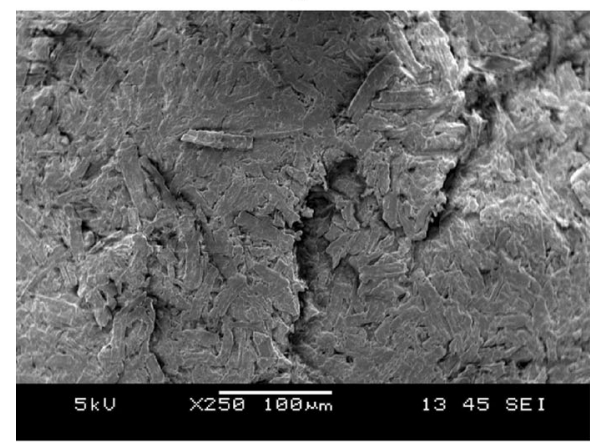

b

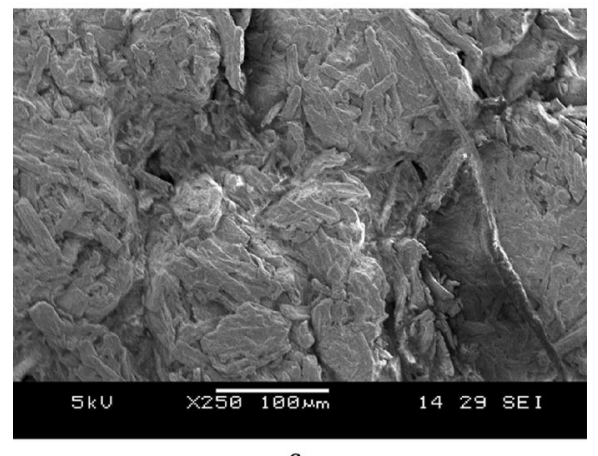

c

Fig. 1. Scanning electron micrographs of a as-received Avicel PH 200 powder containing various shapes of particles, $\mathbf{b}$ compact with $\sim 18$ vol.\% porosity showing the deformed particle shape, and compact with $\sim 56$ vol. $\%$ porosity showing the preserved particle shape

compressed at $37 \mathrm{MPa}$, particle deformation is limited to the interparticle contacts. Accordingly, fracture is mainly due to interparticle separation for porosity levels higher than $\sim 35 \%$. The particle shape and size of as-received Avicel PH 200 are given in Fig. 2a. Deformed particle shapes for $P \simeq 18$ vol.\% (Fig. 2b) and preserved particle shapes for $P \simeq 56$ vol.\% (Fig. 2c) in fractured compacts indicate that higher porosity tablets fail through interparticle separation. As a result, a less steep decrease in $\sigma_{\mathrm{f}}$ is observed for $P>\sim 35 \%$, which is related to the decreasing contact area between particles.

Fracture tests were performed after $24 \mathrm{~h}$ of compaction except for the set with $P=36$ vol. \%, which was performed after 7 days. Haware et al. (5) reported that stored elastic energy is recovered after $24 \mathrm{~h}$ and does not change significantly after up to 7 days for the Avicel PH 105 and other pharmaceutical materials. The majority of the elastic recovery occurs immediately after tablet ejection and is complete after $24 \mathrm{~h}$. The slow recovery is due to the viscoelastic behavior of microcrystalline cellulose (5).
Despite the viscoelastic behavior of MCC, the compacts of Avicel PH 200 were reported to have similar fracture strengths: $7.90 \mathrm{MPa}$ for a compaction speed of $10 \mathrm{~mm} / \mathrm{s}$ and $7.64 \mathrm{MPa}$ for $100 \mathrm{~mm} / \mathrm{s}$ with a dwell time of $0 \mathrm{~s}$ (5). Accordingly, the present fracture strength data for the compaction speed of $0.1 \mathrm{~mm} / \mathrm{s}$ are likely relevant for compacts that are produced at higher speeds.

Mechanical properties of MCC compacts are sensitive to the humidity $(60,61)$. Malamataris et al. reported an initial plateau following a decrease in fracture strength of Avicel PH 101 compacts of $10 \%$ porosity with an increase in relative humidity (60); these compacts have lower porosity than the highest density compacts tested here. Similarly, Amidon and Houghton investigated the effect of moisture on Avicel PH 101 compacts of $\sim 40 \%$ porosity (61). They found that the fracture strength and hardness values were insensitive to the water content of MCC up to $5 \%$ moisture content, which corresponds to $\sim 50 \%$ relative humidity (61). The difference in fracture strength of compacts was $9 \%$, for an increase in relative humidity from about $0 \%$ to $68 \%$ (61). In the present study, all the compacts were tested under a relative humidity level between $31 \%$ and $61 \%$, except one set with 36 vol. $\%$ porosity at $\mathrm{RH}=81 \%$. Accordingly, the effect of humidity on compact strength is expected to be smaller than the effect of porosity. In addition, the fracture strength of the compacts that were tested at $\mathrm{RH}=81 \%$ follow a similar trend compared to the rest of the data and other studies on Avicel PH 102 (53) and Emcocel 90M (37), Fig. 2.

Particle size has been observed to affect fracture behavior of compacted tablets $(8,31,33,62)$. Almaya and Aburub reported that a decrease in particle size from $180-250 \mu \mathrm{m}$ to $<74 \mu \mathrm{m}$ increased the tablet strength $\left(\sigma_{\mathrm{f}}\right)$ for Avicel PH 200 and Avicel PH 302, and decreased the $\sigma_{\mathrm{f}}$ for Avicel PH 102 (all the changes are $<5 \%$ ) (33). In addition, the $\sigma_{\mathrm{f}}$ for



Fig. 2. Effect of porosity on fracture strength of Avicel PH 200 compacts tested under diametral compression is shown for the present study (circle) (average of 50 samples, standard deviations are given in Table I), for Avicel PH 102 flat faced tablets (triangle) digitized from Fig. 4 of (53), and for Emcocel 90M (square) digitized from Fig. 3 of (37). All the data in the figure is fitted to $\sigma_{\mathrm{f}}=\sigma_{\max }-\sigma_{\mathrm{dec}} \exp (-d / P)$, dashed line, which was proposed in our earlier work (27). The fitting parameters are $\sigma_{\max }=12.9, \sigma_{\mathrm{dec}}=16.6, d=14.3$, assuming zero strength at 60 vol. $\%$ porosity 

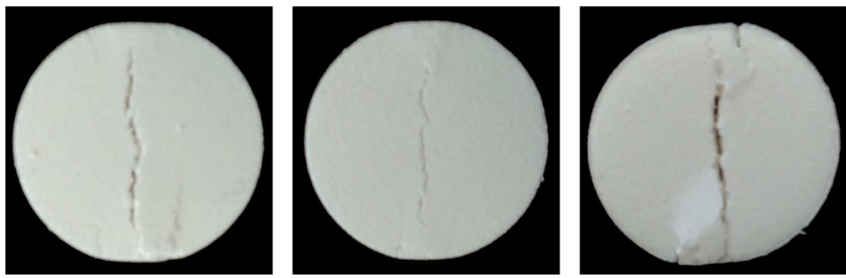

a $P \simeq 17 \%$ c $\quad P \simeq 36 \%$

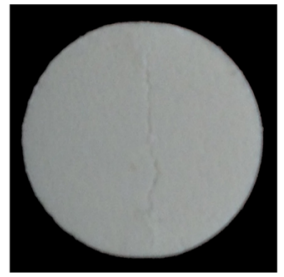

d $P \simeq 40 \%$

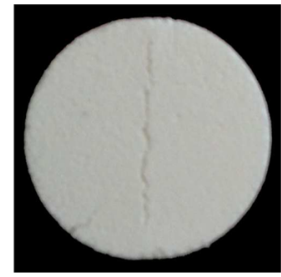

e $P \simeq 45 \%$

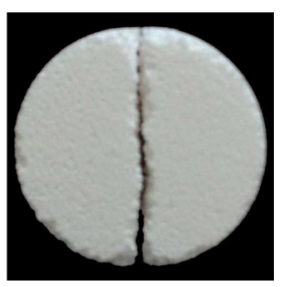

f $P \simeq 56 \%$

Fig. 3. Representative pictures of fractured tablets at various volume percent of porosity, $P$ : a $P \simeq 17 \%$, b $P \simeq 25 \%$, c $P \simeq 36 \%$, d $\mathrm{P} \simeq 40 \%$, e $P \simeq 45 \%$, and $\mathbf{f} P \simeq 56 \%$. Shear cracks in c occur after propagation of the central crack, when the test is not stopped

Avicel PH 101 was shown to increase with decreasing powder size (31). For the Sorbitol Instant compacts, larger particle size $(>710 \mu \mathrm{m})$ resulted in higher tablet strength than smaller ones $(355-500 \mu \mathrm{m})(8)$. The effect of particle size on tablet strength is also dependent on porosity. An increase in porosity results in similar fracture strengths for compacts with different particle sizes; thus, particle size effects are prominent at porosity levels less than $\sim 10 \mathrm{vol} . \%$ (8).

Fracture strength of MCC compacts also depends on the crystal structure and the amount of amorphous phase, which can be induced by deformation. However, different analytical tests result in range of values for the degree of crystallinity; thus, complementary techniques are required to obtain accurate degree of crystallinity (63). The crystallinity of Avicel powders was reported to change with the compaction pressure (64,65). Avicel PH 101, PH 102, and PH 302 show an increase in crystallinity for compaction pressures up to $\sim 10 \mathrm{MPa}$, following a decrease with increasing compassion pressure $(64,65)$. These changes in crystallinity can change the bonding between particles, which can be amorphous to amorphous, amorphous to crystalline, crystalline to crystalline, or mixed. In addition, stresses that arise during compaction are inhomogeneous (66) and the crystallinity is expected to vary throughout the compact. Therefore, bonding strength can vary in tablets, affecting fracture strength, and statistics. Accordingly, the fracture strength of MCC has been reported to decrease with increasing amorphous content (67).

\section{Effect of Porosity on Weibull Modulus of Avicel PH 200 Compacts}

Weibull moduli of the Avicel PH 200 compacts decreased with increasing porosity, i.e., higher porosity compacts have lower reliability (Fig. 4). A statistically significant decrease in $\mathrm{m}$ value from $\sim 35$ at $P \simeq 17 \mathrm{vol}$. \% down to 13 at $P=36 \mathrm{vol} . \%$ is observed. For porosity levels higher than 36 vol. $\%$, moduli stay below 17 up to $P=56$ vol. \%. The Weibull moduli varied even for the sets containing very close porosity levels 16.8 , 17.0, and 18.4 vol.\%. However, the $m$ values are higher than 30 for these three porosity levels, which is higher than for many high quality technical ceramics (38). This observation indicates that the fracture strength can vary from batch to batch even for highly controlled tests.

The increase in Weibull moduli at low porosity levels can be explained through the increased homogeneity of the compacts. To achieve low porosity, MCC powders go through a relatively high plastic deformation, which, in turn, results in similar microstructures; thus, the distribution of compact strength narrows, whereas, at high porosity, the arrangement of powders can vary significantly. As a result, compacts can have pore structures favoring low $\sigma_{\mathrm{f}}$, or if the pores are distributed homogeneously, fracture strength would be higher. The presence of both high and low $\sigma_{\mathrm{f}}$ values decreases Weibull modulus.

Both $\chi^{2}$ and AD goodness-of-fit tests resulted in higher $P$ values for normal distribution than Weibull distribution for compacts with porosity $<18.4$ vol. $\%$ coressponding to the lowest three porosity levels. Higher $P$ values indicate a better fit to the fracture data. All the $P$ values for $\chi^{2}$ and AD tests are given in Table I. The good fits to the normal distribution at low porosity levels $\left(P<20\right.$ vol. \%) assure a safe use of $\sigma_{\mathrm{f}}$ in parametric inference tests. Weibull distribution is favored by the AD test in three of eight sets at $P$ of 25,36, and 56 vol.\% ( $P=56$ vol.\% also favored by the $\chi^{2}$ test $)$. Fracture data at $P=40$ vol. \% fit to normal distribution as good as Weibull because the $P$ values from $\chi^{2}$ and AD tests are very close (Table I). Consequently, a larger number of specimens are required to distinguish between different distributions.

The Weibull plot is a common way to visualize fracture data that are fitted to a Weibull distribution (38). Fracture data for Avicel PH 200 compacts together with the fitted Weibull distributions (dashed lines) are shown in Fig. 5. The fitted distributions result in a line in Weibull plot, where the Weibull modulus is the slope of this line. As the fracture data do not perfectly fit to Weibull distribution, deviations from the straight line occur. Especially in porous materials, pore-pore stress interactions result in various types of deviations: $\mathrm{N}$ (negative), P- (positive), or S-type (28). If the lower tail of a fracture data deviates towards the mean $\sigma_{\mathrm{f}}$, a P-type deviation occurs. If the lower tail of a fracture data deviates away from the mean $\sigma_{\mathrm{f}}$, an N-type deviation occurs. If both the upper and lower tails of a fracture data deviate towards the mean $\sigma_{\mathrm{f}}$, an S-type deviation occurs. The fracture data of the lowest three porosity level fit better to ND; thus, a P-type deviation from WD is observed (Fig. 5). For the fracture data of the highest three porosity levels, P-type deviations are also observed, which represents a group of weaker tablets in the whole fracture data. Whereas, the compacts with 25 and 36 vol.\% porosity do not reveal any strong deviation.

\section{Porosity Versus Weibull Modulus of Avicel PH 200 Compacts: Comparison With Literature and Finite Element Simulations}

The change in Weibull modulus with porosity for Avicel PH 200 compacts, other pharmaceutical tablets, and simulation results is shown in Fig. 6. Table II summarizes the details of the tests under diametral compression, and Table III is for flexural bending. 


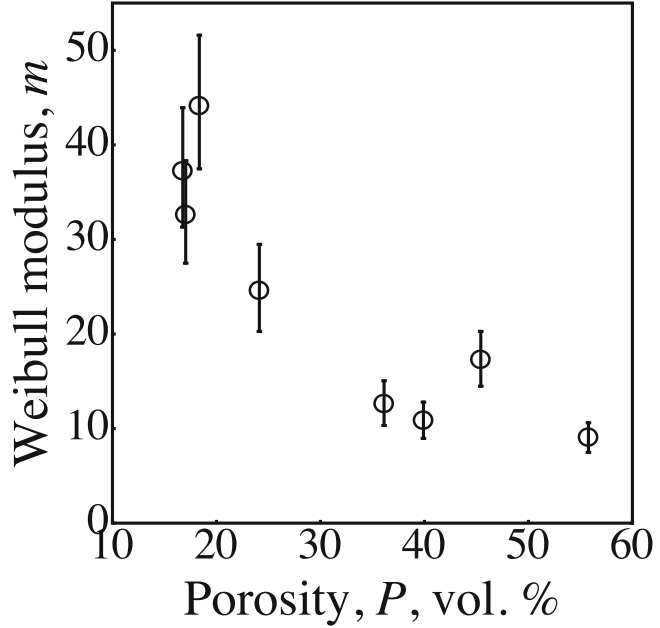

Fig. 4. Weibull modulus as a function of porosity for Avicel PH 200 compacts (circle). Error bars indicate $90 \%$ confidence interval. Details of the tests are given in Table I

The only extended study on Avicel PH 102 is by Sonnergaard (6), which reports the coefficient of variation (CV) for a wide range of materials together with an equation to calculate Weibull modulus from CV. Sonnergaard's study on Avicel PH 102 tablets reports a decrease in $\mathrm{m}$ value for increasing porosity (6), but the Weibull moduli are higher than the moduli of the present Avicel PH 200 compacts. Reasons for the higher modulus could be (a) the use of magnesium stearate as a lubricant, which can affect the fracture behavior and elastic recovery behavior, (b) the use of smaller particle size MCC (Avicel PH 102, with a particle size of $100 \mu \mathrm{m}$ compared to Avicel PH 200 with a particle size of $180 \mu \mathrm{m}$ ), and (c) the low resolution of testing $(1 \mathrm{~N})$, which bins the fracture strength data into $1-\mathrm{N}$ intervals (6).

Sonnergaard reported a similar favoring of normal distribution over Weibull distribution for Avicel PH 102 compacts using the $\chi^{2}$ test (6). The fracture behavior of porous zinc



Fig. 5. Weibull plot showing the effect of porosity on the variability of fracture strength of Avicel PH 200 compacts for (decreasing porosity from left to right): red ex symbol $P \simeq 55.8 \%$,orange ex symbol $P \simeq 45.4 \%$, light orange ex symbol $P \simeq 39.9 \%$, yellow symbol $P \simeq 36.1 \%$, gray ex symbol $P \simeq 25.3 \%$, blue ex symbol $P \simeq 18.4 \%$, violet ex symbol $P \simeq 17.0 \%$, and green ex symbol $P \simeq 16.8 \%$. Dashed lines represent the Weibull fits to each set of fracture data, for which the details are given in Table I



Fig. 6. Weibull modulus as a function of porosity under uniaxial loading for MCC (circle the present study, circle with a horizontal line through it (6)), for aspirin (circle with ex symbol (9)), for lactose monohydrate (LAC) (left triangle (6)), for $50 \% \mathrm{w} / \mathrm{w}$ mixture of MCC-LAC (triangle (6)), for chewable vitamin C tablets from manufacturers A (diamond) B (slash), C (square), and D (hyphen) for sorbitol (right triangle) (8) in black for diametral compression and in red for three-point bend test. Simulation results are shown in plus symbol, brown for $48-\mu \mathrm{m}$, red for $80-\mu \mathrm{m}$, green for $120-\mu \mathrm{m}$, and blue for $160-\mu \mathrm{m}$ diameter pores. Weibull moduli from Sonnergaard's (6) study were calculated using the digitized data from Fig. 7 and Eq. 6. Error bars for the experiments indicate $90 \%$ confidence interval. Error bars for the imulations indicate the standard deviation in three different Weibull moduli estimated from the same set of microstructures with different crack size distributions. Details of the tests are given in Table I for the present study, in Table II for diametral compression, and in Table III for flexural bend tests

oxide is also reported to follow normal distribution better than Weibull (68). Despite the favoring of normal distribution as a fit for the fracture data, the use of ND for reliability calculations is not correct for low stresses because ND is not bounded at zero and can result in negative stress for high reliability calculations.

One hundred tablets of lactose monohydrate (LAC) and mixture of $50 \mathrm{wt} \%$ lactose monohydrate (LAC) and $50 \mathrm{wt} \%$ MCC, which included 0.5 vol. \% magnesium stearate, were tested at three different porosity levels (6). The MCC-LAC mixture showed a decrease in $m$ value as the porosity increased (6) (Fig. 6). However, Weibull modulus for LAC, which is more brittle than MCC, did not change for an increase in porosity from 12 to 19 vol.\% (6) (Fig. 6). The addition of MCC decreases variability in tablet strength, which could mean that the compaction of MCC results in microstructurally similar tablets. Deformability of MCC can result in mechanical interlocking and a more homogenous microstructure; thus, a higher Weibull modulus. On the other hand, a brittle powder would break during compaction, and the resulting tablet could have various sizes of pores and limited mechanical interlocking, which would result in a lower value compared to tablets of deformable materials.

Weibull modulus of commercially available chewable vitamin $\mathrm{C}$ tablets was reported to be between 5 and 16 for a porosity range of $18-31 \%$ without a correlation between porosity and $m$ value (number of specimens $N \simeq 30$ ) (13). In 
Table II. Weibull statistics of various pharmaceutical compacts estimated from diametral compression tests

\begin{tabular}{|c|c|c|c|c|c|c|c|}
\hline Ref. & Material & $M$ & $\sigma_{0}(\mathrm{MPa})$ & $P(\%)$ & $N$ & Tablet geometry & RH (\%) \\
\hline (6) & $\mathrm{MCC}$ & $72^{a}$ & $49.4(2.58) \mathrm{N}^{b}$ & 30 & 100 & Flat face-bevel edged & NS \\
\hline (6) & $\mathrm{MCC}$ & $63^{a}$ & $106.7(2.00) \mathrm{N}^{b}$ & 35 & 100 & Flat face-bevel edged & NS \\
\hline (6) & $\mathrm{MCC}$ & $49^{a}$ & $149(1.76) \mathrm{N}^{b}$ & 45 & 100 & Flat face-bevel edged & NS \\
\hline (6) & LAC & $25^{a}$ & $56.5(4.79) \mathrm{N}^{b}$ & 12 & 100 & Flat face-bevel edged & NS \\
\hline (6) & LAC & $23^{a}$ & $105.6(5.32) \mathrm{N}^{b}$ & 15 & 100 & Flat face-bevel edged & NS \\
\hline (6) & LAC & $26^{a}$ & $134.5(5.02) \mathrm{N}^{b}$ & 19 & 100 & Flat face-bevel edged & NS \\
\hline (6) & MCCLAC & $65^{a}$ & $55.7(2.39) \mathrm{N}^{b}$ & 15 & 100 & Flat face-bevel edged & NS \\
\hline (6) & MCCLAC & $55^{a}$ & $103.0(2.29) \mathrm{N}^{b}$ & 20 & 100 & Flat face-bevel edged & NS \\
\hline (6) & MCCLAC & $53^{a}$ & $134.5(1.95) \mathrm{N}^{b}$ & 27 & 100 & Flat face-bevel edged & NS \\
\hline (13) & Vit. C-A1 & 5.4 & 0.41 & 20 & 30 & Flat face & NS \\
\hline (13) & Vit. C-A2 & 8.4 & 0.48 & 20 & 30 & Flat face & NS \\
\hline (13) & Vit. C-A3 & 13.7 & 0.52 & 19 & 30 & Flat face & NS \\
\hline (13) & Vit. C-A4 & 15.1 & 0.48 & 18 & 20 & Flat face & NS \\
\hline (13) & Vit. C-B1 & 4.6 & 0.78 & 21 & 30 & Flat face & NS \\
\hline (13) & Vit. C-B2 & 2.8 & 0.41 & 25 & 30 & Flat face & NS \\
\hline (13) & Vit. C-B3 & 9.4 & 0.90 & 19 & 20 & Flat face & NS \\
\hline (13) & Vit. C-C1 & 16.8 & 0.95 & 19 & 30 & Flat face & NS \\
\hline (13) & Vit. C-C2 & 10.0 & 0.95 & 20 & 30 & Flat face & NS \\
\hline (13) & Vit. C-D1 & 16.0 & 1.08 & 19 & 30 & Flat face & NS \\
\hline (13) & Vit. C-D2 & 15.0 & 1.18 & 31 & 28 & Flat face & NS \\
\hline (13) & Vit. C-D3 & 8.3 & 1.12 & 18 & 30 & Flat face & NS \\
\hline (13) & Vit. C-D4 & 9.9 & 1.12 & 18 & 20 & Flat face & NS \\
\hline$(8)$ & Sorbitol & 29.5 & $4.40^{c}$ & 7.1 & 32 & Flat face & 53 \\
\hline (8) & Sorbitol & 41.6 & $2.30^{c}$ & 11.9 & 32 & Flat face & 53 \\
\hline (8) & Sorbitol & 15.2 & $1.68^{c}$ & 17.6 & 32 & Flat face & 53 \\
\hline (9) & Aspirin & 12.2 & 1.1 (mean value) & 5 & 1005 & NS & NS \\
\hline
\end{tabular}

$m$ is the Weibull modulus, $\sigma_{0}$ is the characteristic strength, $P$ is the porosity, $N$ is the number of the samples tested, $R H$ is the relative humidity ${ }^{a}$ Weibull modulus is calculated from the coefficient of variation using Eq. 6 in (6)

${ }^{b}$ Average crushing force (unit in Newton) is reported with percent coefficient of variation in parenthesis, see Table II in (6)

${ }^{c}$ Data are digitized from Fig. 3 of (8)

addition, the Weibull moduli did not show any dependence on the testing technique-diametral compression or three-point bending-for different batches (13). Similarly, acetylsalicylic acid tablets had a Weibull modulus of $\sim 12$, which was estimated from a very large data set of 1005 tablets. The strength variation in these 1005 tablets was related to the commercial compaction machines that introduce variation in weight, thickness, and compaction pressure. Consequently, Weibull modulus can fluctuate from batch to batch for the commercial products (9).

An extensive study on sorbitol tablets (12 mm diameter, $4 \mathrm{~mm}$ nominal thickness, $N=32$ ) showed an inverse parabolic

Table III. Weibull statistics of various pharmaceutical compacts estimated from flexural bend tests

\begin{tabular}{|c|c|c|c|c|c|c|c|}
\hline Ref. & Material & $M$ & $\sigma_{0}(\mathrm{MPa})$ & $P(\%)$ & $N$ & Tablet geometry & RH (\%) \\
\hline (13) & Vit. C-A1 & 3.3 & 1.14 & 20 & 30 & Flat face & NS \\
\hline (13) & Vit. C-A2 & 6.3 & 1.44 & 20 & 30 & Flat face & NS \\
\hline (13) & Vit. C-A3 & 8.5 & 1.31 & 19 & 30 & Flat face & NS \\
\hline (13) & Vit. C-A4 & 9.7 & 1.20 & 18 & 20 & Flat face & NS \\
\hline (13) & Vit. C-B1 & 5.8 & 2.67 & 21 & 30 & Flat face & NS \\
\hline (13) & Vit. C-B2 & 2.9 & 1.42 & 25 & 30 & Flat face & NS \\
\hline (13) & Vit. C-B3 & 21.9 & 3.22 & 19 & 20 & Flat face & NS \\
\hline (13) & Vit. C-C1 & 10.9 & 2.83 & 19 & 30 & Flat face & NS \\
\hline (13) & Vit. C-C2 & 9.9 & 3.03 & 20 & 30 & Flat face & NS \\
\hline (13) & Vit. C-D1 & 16.1 & 3.06 & 19 & 30 & Flat face & NS \\
\hline (13) & Vit. C-D2 & 8.2 & 3.04 & 31 & 28 & Flat face & NS \\
\hline (13) & Vit. C-D3 & 10.0 & 3.34 & 18 & 30 & Flat face & NS \\
\hline (13) & Vit. C-D4 & 10.3 & 3.19 & 18 & 20 & Flat face & NS \\
\hline (8) & Sorbitol & 12.99 & $8.87^{a}$ & 6.84 & 32 & Flat face & 53 \\
\hline (8) & Sorbitol & 9.81 & $6.38^{a}$ & 12.20 & 32 & Flat face & 53 \\
\hline (8) & Sorbitol & 8.44 & $4.36^{a}$ & 17.75 & 32 & Flat face & 53 \\
\hline
\end{tabular}

$m$ is the Weibull modulus, $\sigma_{0}$ is the characteristic strength, $P$ is the porosity, $N$ is the number of the samples tested, $R H$ is the relative humidity ${ }^{a}$ Data are digitized from Fig. 4 of (8) 
dependence of Weibull moduli on porosity for diametral compression test, in which the maximum $m$ values were observed at the medium level porosity of $12-13 \%$ compared to $7-10 \%$ and 18-19\% (8). For similar porosity levels, no correlation between porosity and $m$ values was found for three-point bending. Whereas Weibull modulus decreased in three- out of four-test series for ball-on-ring test, which applies a biaxial tensile stress (8).

Different fracture tests can also affect fracture statistics. For example, the maximum tensile stress $\left(\sigma_{\max }\right)$ occur at the surface for a three-point bend test, but $\sigma_{\max }$ occur at the centerline under diametral compression test. On the other hand, the maximum stress affects a larger surface for fourpoint bend test compared to a three-point bend test, which can result in a lower Weibull modulus for the three-point bend test due to decreased probability of finding larger cracks. Similarly, biaxial loading compared to diametral tensile test results in different $m$ values (Fig. 6).

\section{Comparison with Finite Element Simulations}

The same simulation procedure that is used in the present study has been used to describe fracture strength variations in brittle porous materials such as alumina (27) and glass (69) together with the effects of loading conditions (28) and crack orientation (52). The simulations show that, even for relatively homogenous brittle porous materials, Weibull modulus is limited to $\sim 10$ for porosity levels higher than $2 \%$ (Fig. 6). Similar behavior was also observed for a large set of porous hydroxyapatite (70). The main reason behind the upper limit in $\mathrm{m}$ values $(\mathrm{m} \approx 10)$ is the random pore-pore stress interactions $(27)$.

Although the simulated Weibull moduli are similar to $m$ values of aspirin, sorbitol under biaxial loading, and some of the vitamin C tablets, Weibull moduli of Avicel PH 200 compacts with $P<25$ vol.\% are significantly higher than the simulated moduli. Weibull modulus of the simulations at the highest simulated porosity level, $31 \mathrm{vol} . \%$, is $\sim 8$ and close to the modulus of the experimental set at $36 \mathrm{vol} . \%, m \simeq 13$. Simulated porosity was limited to the 31 vol. \% because the microstructures containing $P \geq 31$ vol. \% have to be three-dimensional for accurate representation. Besides, real microstructures have a nonuniform porosity, and MCC is not an isotropic material. Accordingly, simulations that embody these complexities should be performed to understand the fracture behavior of the compacted MCC powders.

\section{CONCLUSION}

The effect of porosity on fracture behavior of Avicel $\mathrm{PH}$ 200 powders was investigated through diametral compression tests across eight different porosity levels, each set containing $\sim 50$ samples. Based on the experiments, the following conclusions can be made:

1. Weibull modulus of Avicel PH 200 MCC compacts decreases with increasing porosity.

2. P-type deviations from Weibull statistics have been observed for microstructures containing porosity $<19$ vol. $\%$ and more than $40 \mathrm{vol} . \%$, i.e., lower tail of the fracture data deviates towards the mean fracture stress.

3. Normal distribution fits better to the fracture data of compacts with $P<20 \%$, whereas Weibull distribution is a better fit to fracture data for $P=56$ vol. $\%$.
4. The change in fracture strength of MCC compacts with porosity is described by the function: $\sigma_{\mathrm{f}}=\sigma_{\max }-\sigma_{\mathrm{dec}} \exp (-d /$ $P$ ), which is based on 840 unique finite element simulations on porous microstructures (27).

5. Two-dimensional FEM simulations have to be extended to realistic three-dimensional microstructures to investigate fracture behavior of compacted MCC powders.

Pharmaceutical tablets not only have to be strong enough to withstand stresses that arise during processing and transportation but also have to be user friendly, i.e., elderly people should be able to break the tablets into half by hand or kids should be able to masticate a chewable vitamin tablet without any damage to their teeth or mandibular joints (13). However, compacted powders are brittle; thus, fracture strength inherently varies even for the nominally identical specimens (39). The present study provides a high-quality fracture data to compare with threedimensional discrete element simulations of tablet strength, which are good at capturing the strength, but fall short in accurately describing the strength variability (71). Further experiments and advanced simulations are required for an improved understanding of fracture strength variations in pharmaceutical tablets.

\section{ACKNOWLEDGEMENTS}

Authors greatly acknowledge FMC BioPolymer for supplying Avicel PH 200 powders. ÖK and KJB thank Erin Colleen Cummings for generating the preliminary fracture data.

\section{REFERENCES}

1. Roberts R, Rowe R, York P. The measurement of the critical stress intensity factor (KIC) of pharmaceutical powders using three point single edge notched beam (SENB) testing. Int J Pharm. 1993;91(2):173-82.

2. Hancock BC, Clas SD, Christensen K. Micro-scale measurement of the mechanical properties of compressed pharmaceutical powders. 1: the elasticity and fracture behavior of microcrystalline cellulose. Int J Pharm. 2000;209(1):27-35.

3. Inman S, Briscoe B, Pitt K, Shiu C. Axial tensile fracture of micro4 crystalline cellulose compacts. Int J Pharm. 2008;349(1):172-9.

4. Zinchuk AV, Mullarney MP, Hancock BC. Simulation of roller compaction using a laboratory scale compaction simulator. Int $\mathbf{J}$ Pharm. 2004;269(2):403-15.

5. Haware RV, Tho I, Bauer-Brandl A. Evaluation of a rapid approximation method for the elastic recovery of tablets. Powder Technol. 2010;202(1):71-7.

6. Sonnergaard JM. Distribution of crushing strength of tablets. Eur J Pharm Biopharm. 2002;53(3):353-9.

7. Stanley P. Mechanical strength testing of compacted powders. Int J Pharm. 2001;227(1):27-38.

8. Podczeck F. Investigations into the mechanical strength anisotropy of Sorbitol Instant compacts made by uniaxial compression. Adv Powder Technol. 2007;18(4):361-79.

9. Kennerley J, Newton J, Stanley P. A modified Weibull treatment for the analysis of strength-test data from non-identical brittle specimens. J Mater Sci. 1982;17(10):2947-54.

10. Stanley P, Newton J. Variability in the strength of powder compacts. J Powder Bulk Solids Technol. 1977;1:13-9.

11. Kennerley J. Variability in the mechanical strength of tablets. Acta Pharm Technol Suppl. 1979;7:53-6. 
12. Podczeck F. Methods for the practical determination of the mechanical strength of tablets-from empiricism to science. Int J Pharm. 2012;436(1):214-32.

13. Ambros MC, Podczeck F, Podczeck H, Newton JM. The characterization of the mechanical strength of chewable tablets. Pharm Dev Technol. 1998;3(4):509-15.

14. Weibull W. A statistical theory of the strength of materials. Swedish Royal Institute for Engineering Research, 1939; p. 1-45.

15. Weibull W. A statistical distribution function of wide applicability. J Appl Mech. 1951;18(3):293-7.

16. Pitchumani R, Zhupanska O, Meesters GM, Scarlett B. Measurement and characterization of particle strength using a new robotic compression tester. Powder Technol. 2004;143:56-64.

17. Salako M, Podczeck F, Newton JM. Investigations into the deformability and tensile strength of pellets. Int J Pharm. 1998;168(1):49-57.

18. Sonnergaard JM. A new brittleness index for compacted tablets. J Pharm Sci. 2013;102(12):4347-52.

19. Nelson K, Wang L. Determination of time course of tablet disintegration II: method using continuous functions. J Pharm Sci. 1978;67(1):86-9.

20. Langenbucher F. Letters to the Editor: Linearization of dissolution rate curves by the Weibull distribution. J Pharm Pharmacol. 1972;24(12):979-81.

21. Costa P, Sousa Lobo JM. Modeling and comparison of dissolution profiles. Eur J Pharm Sci. 2001;13(2):123-33.

22. Elkoshi Z. On the variability of dissolution data. Pharm Res. 1997;14(10):1355-62.

23. Ogden J. Weibull shelf-life model for pharmaceuticals. Pharm Technol. 1978;2(10):45-9.

24. Castillo S, Villafuerte L. Compactibility of ternary mixtures of pharmaceutical powders. Pharm Acta Helv. 1995;70(4):329-37.

25. Kachrimanis K, Nikolakakis I, Malamataris S. Tensile strength and disintegration of tableted silicified microcrystalline cellulose: influences of interparticle bonding. J Pharm Sci. 2003;92(7):1489-501.

26. Bolhuis GK, Chowhan ZT. Materials for direct compaction. Drugs Pharm Sci. 1996;71:419-500.

27. Keleş Ö, Garcia RE, Bowman KJ. Stochastic failure of isotropic, brittle materials with uniform porosity. Acta Mater. 2013;61(8): 2853-62.

28. Keleş Ö, Garcia RE, Bowman KJ. Deviations from Weibull statistics in brittle porous materials. Acta Mater. 2013;61(19): 7207-15.

29. Sonnergaard JM. Quantification of the compactibility of pharmaceutical powders. Eur J Pharm Biopharm. 2006;63(3):270-7.

30. Porion P, Busignies V, Mazel V, Leclerc B, Evesque P, Tchoreloff P. Anisotropic porous structure of pharmaceutical compacts evaluated by PGSTE-NMR in relation to mechanical property anisotropy. Pharm Res. 2010;27(10):2221-33.

31. Kachrimanis K, Malamataris S. Compact size and mechanical strength of pharmaceutical diluents. Eur J Pharm Sci. 2005;24(2):169-77.

32. Levis S, Deasy P. Pharmaceutical applications of size reduced grades of surfactant co-processed microcrystalline cellulose. Int J Pharm. 2001;230(1):25-33.

33. Almaya A, Aburub A. Effect of particle size on compaction of materials with different deformation mechanisms with and without lubricants. AAPS PharmSciTech. 2008;9(2):414-8.

34. Obae K, Iijima H, Imada K. Morphological effect of microcrystalline cellulose particles on tablet tensile strength. Int J Pharm. 1999;182(2):155-64.

35. Igwilo CI, Pilpel N. Effects of coating the powder on the tensile strength, disintegration and dissolution of lactose tablets. Int $\mathrm{J}$ Pharm. 1983;15(1):73-85.

36. Chao LY, Shetty DK. Reliability analysis of structural ceramics subjected to biaxial flexure. J Am Ceram Soc. 1991;74(2):333-44.

37. Van Veen B, Bolhuis G, Wu Y, Zuurman K, Frijlink H. Compaction mechanism and tablet strength of unlubricated and lubricated (silicified) microcrystalline cellulose. Eur J Pharm Biopharm. 2005;59(1):133-8.

38. Wachtman JB, Cannon WR, Matthewson MJ. Mechanical properties of ceramics. John Wiley \& Sons Inc; 2009

39. Lawn BR. Fracture of brittle solids. Cambridge University Press; 1993
40. Freudenthal AM. Statistical approach to brittle fracture. In: Fracture: an advanced treatise, vol. 2. Academic Press, New York; 1968. p. 591-619.

41. Poloniecki JD, Wilshaw TR. Determination of surface crack size densities in glass. Nature. 1971;229(8):226-7.

42. Jayatilaka AS, Trustrum K. Statistical approach to brittle fracture. J Mater Sci. 1977;12(7):1426-30.

43. Gerguri S, Fellows LJ, Durodola JF, Fellows NA, Hutchinson AR, Dickerson T. Prediction of brittle failure of notched graphite and silicon nitride bars. Appl Mech Mater. 2004;1:113-20.

44. 843-1 E. Advanced technical ceramics, monolithic ceramics, mechanical tests at room temperature. Part 1: Determination of flexural strength; 1995

45. Xu Y, Cheng L, Zhang L, Yan D, You C. Optimization of sample number for Weibull function of brittle materials strength. Ceram Int. 2001;27(2):239-41.

46. European Pharmacopoeia. Strasbourg: European Directorate for the Quality of Medicines and Healthcare; 2010.

47. United States Pharmacopoeia/National Formulary (USP35/ NF30). Rockville, MD: The United States Pharmacopoeial Convention; 2011.

48. Sun CC. True density of microcrystalline cellulose. J Pharm Sci. 2005;94(10):2132-4.

49. Zavaliangos A, Galen S, Cunningham J, Winstead D. Temperature evolution during compaction of pharmaceutical powders. J Pharm Sci. 2008;97(8):3291-304.

50. Timoshenko S. Theory of elasticity. New York: McGraw Hill; 1934.

51. Trustrum K, Jayatilaka ADS. On estimating the Weibull modulus for a brittle material. J Mater Sci. 1979;14(5):1080-4.

52. Keleş Ö, Garcia RE, Bowman KJ. Pore-crack orientation effects on fracture behavior of brittle porous materials. Int $\mathrm{J}$ Fract. 2014;187(2):293-9.

53. Shang C, Sinka I, Jayaraman B, Pan J. Break force and tensile strength relationships for curved faced tablets subject to diametrical compression. Int J Pharm. 2013;442(1):57-64.

54. Bal'shin MY. Relation of mechanical properties of powder metals and their porosity and the ultimate properties of porous metalceramic materials. Dokl Akad Nauk SSSR. vol. 67 [5]; 1949. p. 831-834.

55. Fan X, Case ED, Ren F, Shu Y, Baumann MJ. Part II: Fracture strength and elastic modulus as a function of porosity for hydroxyapatite and other brittle materials. J Mech Behav Biomed Mater. 2012;8:99-110.

56. Ryshkewitch E. Compression strength of porous sintered alumina and zirconia. J Am Ceram Soc. 1953;36(2):65-8.

57. Duckworth W. Discussion of Ryshkewitch paper. J Am Ceram Soc. $1953 ; 36(2): 68$.

58. Sixsmith D. The effect of compression on some physical properties of microcrystalline cellulose powders. J Pharm Pharmacol. 1977;29(1):33-6.

59. Kloefer B, Henschel P, Kuentz M. Validity of a power law approach to model tablet strength as a function of compaction pressure. AAPS PharmSciTech. 2010;11(1):467-71.

60. Malamataris S, Goidas P, Dimitriou A. Moisture sorption and tensile strength of some tableted direct compression excipients. Int J Pharm. 1991;68(1):51-60.

61. Amidon GE, Houghton ME. The effect of moisture on the mechanical and powder flow properties of microcrystalline cellulose. Pharm Res. 1995;12(6):923-9.

62. York P, Bassam F, Rowe R, Roberts R. Fracture mechanics of microcrystalline cellulose powders. Int J Pharm. 1990;66(1):143-8.

63. Shah B, Kakumanu VK, Bansal AK. Analytical techniques for quantification of amorphous/crystalline phases in pharmaceutical solids. J Pharm Sci. 2006;95(8):1641-65.

64. Kumar V, Kothari SH. Effect of compressional force on the crystallinity of directly compressible cellulose excipients. Int J Pharm. 1999;177(2):173-82.

65. Ek R, Wormald P, Iversen T, Nystrom C, et al. Crystallinity index of microcrystalline cellulose particles compressed into tablets. Int J Pharm. 1995;125(2):257-64.

66. Sinka I, Cunningham J, Zavaliangos A. Analysis of tablet compaction. II: finite element analysis of density distributions in convex tablets. J Pharm Sci. 2004;93(8):2040-53. 
67. Suzuki T, Nakagami H. Effect of crystallinity of microcrystalline cellulose on the compactability and dissolution of tablets. Eur J Pharm Biopharm. 1999;47(3):225-30.

68. Lu C, Danzer R, Fischer FD. Fracture statistics of brittle materials: Weibull or normal distribution. Phys Rev E. 2002;65(6):067102.

69. Keleş Ö, Garcia RE, Bowman KJ. Failure variability in porous glasses: stress interactions, crack orientation, and crack size distributions. Journal of the American Ceramic Society. 2014;97:3967-3972.

70. Fan X, Case ED, Ren F, Shu Y, Baumann MJ. Part I: Porosity dependence of the Weibull modulus for hydroxyapatite and other brittle materials. J Mech Behav Biomed Mater. 2012;8(0):21-36.

71. Siiria SM, Antikainen O, Heinamaki J, Yliruusi J. 3d simulation of internal tablet strength during tableting. AAPS Pharmscitech. 2011;12(2):593-603. 